\title{
Biogeochemical clues to the isotopic mystery of Saratoga Springs
}

\author{
G. LOLLAR ${ }^{1 *}$, O. WARR ${ }^{2}$, E. RUTLEDGE ${ }^{1}$, M. OSBURN ${ }^{3}$
}

${ }^{1}$ Dept of Earth and Environmental Sciences, Rensselaer Polytechnic Institute, USA

*correspondence: garnet.lollar@mail.utoronto.ca

${ }^{2}$ Dept of Earth Sciences, Univ. of Toronto, Canada

${ }^{2}$ Dept of Earth and Planetary Sci., Northwestern Univ., USA

$\mathrm{CO}_{2}$-rich terrestrial hydrothermal springs continue to be of scientific interest for topics as diverse as the origin of the dissolved $\mathrm{CO}_{2}$, fracture-controlled fluid flow, and/or diffusive transport of fluid and gases. While $\delta^{18} \mathrm{O}$ and $\delta^{2} \mathrm{H}$ signatures above the Global Meteoric Water Line (GMWL) have previously been identified in deep crustal fluids in the Precambrian basement, such signatures are rare in Paleozoic sedimentary basins ${ }^{1,2}$. The mineral water springs in Saratoga Springs, New York were suggested to have a crystalline brine component in a past study ${ }^{3}$, but there is little evidence as yet to constrain the mixing end-member or to evaluate other proposed mechanisms such as $\mathrm{CO}_{2}$-water ${ }^{18} \mathrm{O}$ fractionation. Further, to date no study has investigated the microbial communities associated with these fluids, or what clues to the origin they may provide.

The springs originate in the Ordovician Gailor Dolostone overlying the Precambrian basement. Springs discharge via a system of artesian wells from up to $250 \mathrm{~m}$ below surface, through a shale caprock, along a fault line associated with the Appalachian Orogeny. The springs are cold $\left(\sim 10^{\circ} \mathrm{C}\right)$ and have elevated total dissolved solids (TDS), generally increasing with depth up to $\sim 14,000 \mathrm{mg} / \mathrm{L}$. There are also fresh water springs (TDS of $\sim 120 \mathrm{mg} / \mathrm{L}$ ) in the glacial till aquifer closest to the surface. The brines all have tritium values of $\leq 1.4 \pm$ $\sim 0.2$ T.U. in contrast to $\sim 6$ T.U. for the freshwaters. $\delta^{18} \mathrm{O}$ values range from -9.5 to -11.1 permil and $\delta^{2} \mathrm{H}$ from -58 to 68 permil. Intriguingly, in this study, these values lie on a clear horizontal trend to the left of the GMWL, unusual for Paleozoic-hosted sedimentary basin brines.

Using a suite of biogeochemical approaches including noble gas analysis and biomass samples, we investigate the nature of the gas, fluid, and microbial communities in this setting. We evaluate the possibilities of isotopic equilibration between water and $\mathrm{CO}_{2}$ in these gas-rich fluids, and potential mixing with fluid components from the underlying crystalline basement.

${ }^{1}$ Lollar et al. (2019) Geomicro J. 36:(10), 859-872. ${ }^{2}$ Warr et al. (2018) GCA 222, 340-362. ${ }^{3}$ Siegel et al. (2004) Geology. 32. 10.1130/G20094.1. 